\title{
COVID-19 changes to the pregnancy and birth assistance: Catalan midwives' experience
}

\author{
Pablo Rodríguez Coll1,2, Eva Gilaberte Martínez², Dolores Roca Falip², Ramón Escuriet Peirón ${ }^{1,3}$
}

\section{Dear Editor,}

At the beginning of January 2020 in Wuhan (China), a new and highly contagious RNA virus (SARS-CoV-2) was identified by the Chinese authorities ${ }^{1}$. This virus caused the COVID-19 disease, which may be asymptomatic or have respiratory or gastrointestinal symptoms that range from mild to severe. Two months later, the World Health Organization (WHO) declared COVID-19 as a global pandemic pointing to the almost 120000 cases of coronavirus illness in more than a hundred countries around the world.

The first wave of the COVID-19 pandemic in Spain changed drastically our sanitary healthcare outlook and specifically midwives' work. Firstly, many maternity hospitals had to transfer their women and families to third-level hospitals because they were on the verge of collapsing. Secondly, hundreds of midwives were assigned to different services since their delivery rooms were closed, whereas other maternity hospitals saw a significant increase in their workload with a considerable lack of resources and have even restricted partner's presence for the women in labor.

Thirdly, in healthcare facilities, there was a significant reduction in the number of faceto-face consultations to prevent the spread of the virus and decrease people's movement and gathering.

Despite the decrease in the birth rates by $4.2 \%$ in the first half of $2020^{2}$, in the area of healthcare belonging to the north Barcelona region, the Germans Trias and Pujol Hospital had increased by $10 \%$ the number of births attended due to the closing of the Espiritu Santo birth Hospital ${ }^{3}$. Another important aspect to take into account is the increase in the number of coordinated hospital discharges of postpartum women (between 24 and 32 hours) with primary healthcare by $366 \%$ (from 89 in 2019 to 415 in 2020) ${ }^{3}$. This program started in 2017 and was created to ensure the continuity of care, where the postpartum women are visited by the community midwives at home providing quality, holistic, familycentered care.

Regarding our hospital breastfeeding rates, we observed an increase of $21.6 \%$ in exclusive breastfeeding. However, there is also an increase of $6.33 \%$ in the formula feeding willingness (from 4.2\% in 2019 to 10.5\% in 2020). Furthermore, the breastfeeding dropout rate during the hospital stay was $2.6 \%$.

Therefore, the pandemic dramatically changed professionals' and women's minds regarding pregnancy and birth assistance. However, little is known about midwives' experience in providing care during the pandemic in Spain so far ${ }^{4}$. The recently empowered women and families have led to a confusing paradigm where they turn to their selflearning in pregnancy and breastfeeding aspects due to the midwife's support absence during pregnancy and birth, contrary to the individualized 'one-to-one care' established by the World Health Organization Intrapartum Care Initiative ${ }^{5}$ and the Care Strategy for Normal Childbirth 6 . In our healthcare referral area, not only midwives have experienced professional and personal challenges during the pandemic related to remote consultation training and strict infection control equipment and procedures when attending women and their families, but also have experienced the lack of breastfeeding counseling and emotional support to women and families attended, increased the use of formula-feeding and early breastfeeding retirement. Furthermore, midwives refer to missed opportunities to identify important issues such as domestic violence, mental health problems, or women with language problems in the virtual antenatal visits.

Policymakers and organizations should consider lessons learned to support the fact that midwives are a valuable resource that needs enough human staff, equipment and

\section{AFFILIATION}

1 GHenderS Research Group, Blanquerna School of Health Science, University Ramon Llull, Barcelona, Spain

2 Department of Obstetrics and Gynecology, Germans Trias and Pujol Hospital, Barcelona, Spain 3 Health and Integrated Care division, Catalan Health Service, Barcelona, Spain

\section{CORRESPONDENGE TO}

Pablo Rodríguez Coll.

Department of Obstetrics and Gynecology, Germans Trias and Pujol Hospital, Carretera de Canyet s/n, Badalona, 08916, Barcelona, Catalonia, Spain. E-mail: pablo.rodriguez.coll@ gmail.com ORCIDID: https:// orcid.org/0000-0002-92964178

\section{KEYWORDS}

antepartum care, childbirth education, intrapartum care, midwifery professional issues, public health

$\nabla$

Received: 8 June 2021

Accepted: 10 June 2021 
support to provide safe and respectful, holistic and family-centered care to women and their families in future health crises.

\section{REFERENGES}

1. Centers for Disease Control and Prevention. COVID-19. cdc.gov. Accessed May 29, 2021. https://www.cdc.gov/ coronavirus/2019-ncov/index.html

2. Instituto Nacional de Estadística. Vital Statistics (Births, Deaths and Marriages)): First Half of 2020. Provisional Data. Instituto Nacional de Estadística Press Release. January 26, 2021. Accessed May 15, 2021. https://www.ine.es/en/ prensa/mnp_1s2020_p_en.pdf

3. SAP Netweaver. Version 7200.3.8.1067. Accessed May 2, 2021. https://www.sap.com/greece/products/netweaverplatform.html

4. González-Timoneda A, Hernández Hernández V, Pardo Moya S, Alfaro Blazquez R. Experiences and attitudes of midwives during the birth of a pregnant woman with COVID-19 infection: A qualitative study. Women Birth. 2020:1-8. doi:10.1016/j.wombi.2020.12.001

5. WHO recommendations: Intrapartum care for a positive childbirth experience. World Health Organization; 2018. Accessed May 20, 2021. http://www.who.int/reproductivehealth/publications/intrapartum-care-guidelines/en/

6. Strategy for Assistance at Normal Childbirth in the National Health System 2007. Ministry Of Health And Consumers' Affaires; 2008. Healthcare 2007. Accessed May 20, 2021. http://www.mscbs.gob.es/organizacion/sns/ planCalidadSNS/pdf/equidad/estrategiaPartoNormalEnglish.pdf

\section{ACKNOWLEDGEMENTS}

The authors thank the Hospital Germans Trias I Pujol for the data obtained and the help drafting this letter to the editor.

\section{CONFLICTS OF INTEREST}

The authors have completed and submitted the ICMJE Form for Disclosure of Potential Conflicts of Interest and none was reported.

\section{FUNDING}

There was no source of funding for this research

ETHIGAL APPROVAL AND INFORMED CONSENT

Ethical approval and informed consent were not required for this study.

\section{PROVENANGE AND PEER REVIEW}

Not commissioned; internally peer reviewed. 